\title{
Ecological Interactions of Visceral Leishmaniasis in the State of Bahia, Brazil
}

\author{
Italo A Sherlock
}

Centro de Pesquisas Gonçalo Moniz-FIOCRUZ, Rua Valdemar Falcão 121, 40295-001 Salvador, BA, Brasil

The laboratory and field observations summarized in this paper on visceral leishmaniasis ecology in the State of Bahia, Brazil are based on the author's observations over the past 35 years in a number of state's foci, public health records and literature citations. The disease is endemic with epidemic outbreaks occurring every ten years and its geographical distribution is expanding rapidly in the last years. Leishmania chagasi is the main ethiologic agent of the visceral leishmaniasis but Le. amazonensis s. lato was the only leishmania isolated by other authors from some visceral leishmaniasis human cases in the state. Lutzomyia longipalpis (with one or two spots on tergites III and IV and two sized different populations) was epidemiologically incriminated as the main vector. It was found naturally infected with promastigotes, and it was infected with four species of leishmanias in the laboratory. Although the experimental transmission of Le. amazonensis by the bite of Lu. longipalpis to hamsters was performed, the author was not successful in transmitting Le. chagasi in the same way. The dog is the most important domestic source for infection of the vector, however it is not a primary reservoir. The opossum Didelphis albiventris was found naturally infected with Le. chagasi but its role as reservoir is unknown. Foxes and rodents were not found infected with leishmanias in Bahia.

Key words: visceral leishmaniasis - ecology - epidemiology - geographical distribution - dispersion - reservoirs Leishmania chagasi - Leishmania amazonensis s.l. - Lutzomyia longipalpis

The existing agrarian practices and exploitation of the soil result in a minority maintaining large tracts of non-produtive land. Because of this, the majority of the population live at the poverty level in unsanitary housing, poorly nourished, and possibly with decrease of the immunity. In addition, the cessation of surveillance against endemic diseases makes the rural inhabitants easy prey for several infectious diseases, including visceral leishmaniasis that is now spread throughout many municipalities of Bahia where the incidence of the disease is one of the highest of Brazil (Alencar 1959, Marzochi \& Marzochi 1994).

It is possible to control visceral leishmaniasis at a temporary level by means of three simultaneous measures: treatment of human cases, elimination of sick dogs and spraying of insecticides to kill the vector. However, it is not possible to obtain a permanent control of the disease, since, as soon as the vector control is interrupted, the disease continues its natural course (Sherlock 1992).

This work received financial support from the International Development Research Centre Canada (IDRC) and Conselho Nacional do Desenvolvimento Científico e Tecnológico (CNPq), Brazil.

Fax: +55-71-359.4292

Received 31 January 1996

Accepted 14 August 1996
The complex eco-epidemiological web which characterizes the picture of visceral leishmaniasis is not yet well understood. So, basic questions remain without full answers, such as: is there an American primary reservoir for Leishmania chagasi, or is this leishmania a single strain of Le. infantum, introduced with dogs from Europe, that have infected American mammals and spread throughout the continent? (Momem et al. 1987, Grimaldi Jr et al. 1989). What are the real roles of the already known hosts (man, dogs, foxes, opossums and rats) in the natural chain of transmission of visceral leishmaniasis? Does Lutzomyia longipalpis sibling species complex have identical vector capacity from Central to South America? Where are the natural breeding places of this vector?

The data I have obtained on laboratory and field observations over the last 35 five years about the ecology of visceral leishmaniasis in the State of Bahia are wholly presented in this paper, although papers on some aspects of the natural history of visceral leishmaniasis in the State of Bahia have already been published by other authors or by myself and collaborators (Pessoa et al. 1955, Lopes \& Sarno 1956, Sherlock 1964, Sherlock \& Santos 1964, Sherlock 1969, Sherlock \& Almeida 1969, Sherlock \& Guitton 1969a,b, Sherlock \& Almeida 1970, Teixeira 1980, Sherlock et al. 1984, Badaró et al. 1986a,b, Barral et al. 1986, Badaró 1988, Sherlock 1987, Sherlock et al. 1988a,b, Sherlock \& Miranda 1992, Cunha et al. 1995). 


\section{MATERIALS AND METHODS}

Although several foci in the state have been visited, this paper is based mainly on observations made in the endemic focus of Jacobina, Bahia. The records of human cases from the public health services (Fundação Nacional de Saúde and Secretaria Estadual de Saúde) and the literature records, were also considered to make conclusions about geographical distribution, dispersion and epidemic outbreaks of visceral leishmaniasis in the state.

Many data on patients with visceral leishmaniasis were obtained from Dr R Badaró and his clinical staff in Jacobina, who have diagnosed most of the human cases, by means of several methods, including serology and isolation of leishmanias from bone marrow and spleens (Badaró et al. 1986 a,b; Barral et al. 1986, Badaró 1988). Sometimes in other foci, the clinical and laboratorial diagnosis was performed by the author himself (Sherlock 1964, Sherlock \& Santos 1964).

For diagnosis of the infected animals and isolation of the parasites, besides complement fixation reaction and immune-fluorescent-test, other techniques were employed, such as culture of leishmania in several media (NNN, LIT, RPMI, BHI), Giemsa stained smears of organs, inoculation of macerates of organs into hamsters and subsequent confirmation of the hamster infection after three to six months later, histopathologic study of organs and "xenodiagnosis" with sandflies. These proceedings were performed by the author and his collaborators (Sherlock 1964, Sherlock \& Almeida 1970, Sherlock \& Sherlock 1972, Sherlock et al. 1984,1987, 1988a,b, Sherlock \& Miranda 1992).

Only in the last years, the identification of the species of leishmania were confirmed by means of leishmanial specific monoclonal antibody reactions through either indirect radioimmune binding assay or immunofluorescent and immunoperoxidase techniques. These identifications were performed by G Grimaldi Jr and his staff at Oswaldo Cruz Institute (Sherlock et al. 1984).

Dogs, opossums, hamsters, rats and Swiss mice were challenged with leishmanias, by mean of injections of culture promastigotes, suspensions of macerates of infected organs (liver, spleen and skin), macerates of infected sandflies, or by feeding infected sandflies on them. The injections were intraperitoneally for Le. chagasi and intradermically for Le. amazonensis. Usually the challenged animals were observed for six or more months.

Over the years, the author and his staff have performed several dogs surveys in the endemic foci of the state, generally for indication of control measures, but sometimes to get data on the inci- dence and geographical distribution of the disease. Usually, on the same opportunities, samples of sandflies were obtained to determine the vector fauna of the state.

Sandflies were collected from caves, animal burrows, domestic and peridomestic sites with animal baits and light traps, according to the techniques already described (Sherlock \& Pessoa 1964). Part of the collected flies was examined for flagellates and also to produce eggs for maintaining laboratory colonies.

Twenty four hours of consecutive collections and monthly collections were performed inside houses and in caves during two years, to check the vector hourly biting activity and seasonal variation.

Our main project of studies on the ecology of American visceral leishmaniasis was set in the suburb "Grotinha", in Jacobina town, where human and canine cases have been occurring in the last years and there is a high density of Lu. longiplapis. Grotinha is a little peripheral valley, with a disorderly row of houses along a tortuous way, between mountains. These geographic characteristics have been emphasized as typical for most of the Brazilian endemic foci (Deane 1956) (Fig. 1).

\section{RESULTS}

Geographical distribution - Dispersion - Epidemics - Since the first findings of human cases of American visceral leishmaniasis, by means of viscerotomy for yellow fever, done by Penna (1934), until the review done by Sherlock (1964), the geographical distribution of the disease in the State of Bahia, was limited to the central inland plateau "Chapada Dimantina", between 10 and 15 $\mathrm{S}$ and 40 and $43 \mathrm{~W}$ Gr. (Fig. 2).

The early affected areas had a hot and dry climate and about $550 \mathrm{~mm}$ of annual rainfall. The vegetation was predominantly xerophilous. Visceral leishmaniasis did not occur in the humid zones with broadleaf forests and in the Atlantic border with tropical littoral forests.

From that time on, the disease has been spreading rapidly throughout the state, even reaching localities in the coastal zone and in the periphery of big cities, where prior ecological characteristics were supposed to be inadequate for the distribution of the vector $\mathrm{Lu}$. longipalpis. A single human case, probably not autocthonous, had been registered by Penna (1934) for the municipality of Conde, in the littoral. Now, visceral leishmaniasis is endemic in Conde, and also in some other littoral localities. Only areas in the south of Bahia, where dense forests still exist and the climate is tropical humid, have been spared of the disease. 


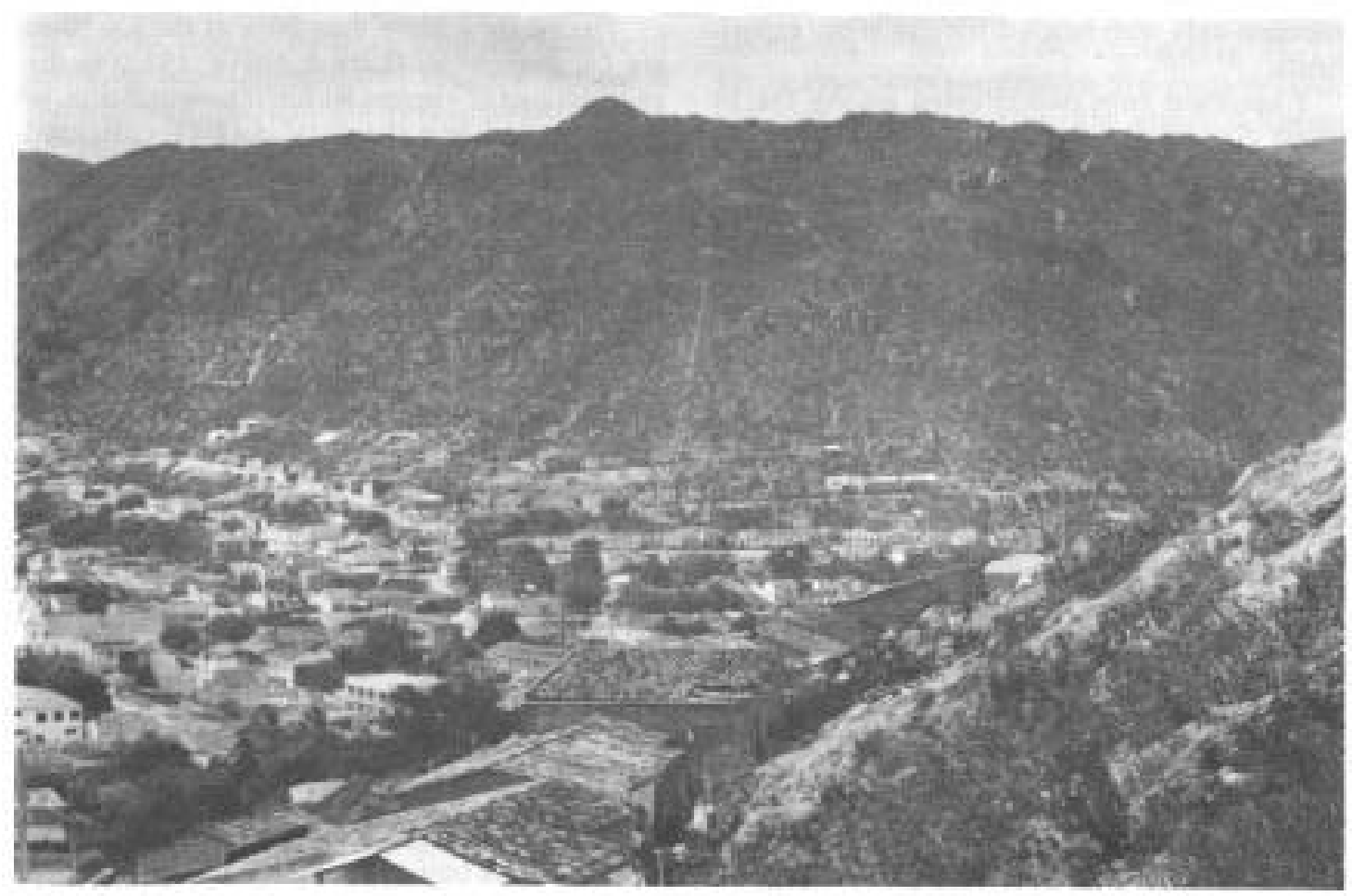

Fig. 1: partial view of the endemic focus of Jacobina, State of Bahia, Brazil.

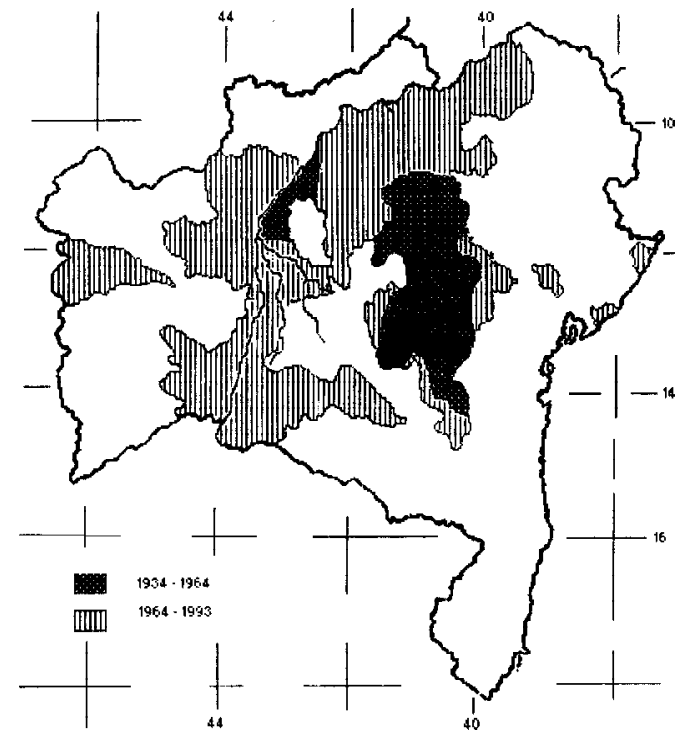

Fig. 2: geographical distribution and dispersion of visceral leishmaniasis in the State of Bahia, Brazil.

Visceral leishmaniasis, in the last four decades, has been occurring endemically with cyclic decennial epidemics. Every epidemic remains for about three years and after that, the number of new cases begins to decline until the endemic condition. Al- though this fact is well perceived in pratice it could not yet be statiscally proved, because notifications of leishmaniases cases to the public health services are usually unreliable. Patients are unregistered, there are under reporting, more than one notification for a same case, distortion on the authocthonicity and even mistakes to denominate the pathologic forms of the leishmaniases, and their names are reported erroneously as visceral or tegumentary. Only in some areas of Brazil, where the data is well monitored in some extent (Teixeira 1980, Costa et al. 1990, Jeronimo et al. 1994) one can easily recognize the decennial incidence of the epidemics which tend to peak in the years ending with number three.

The parasite - According to the taxonomy of the leishmanias presented by Shaw (1993), Le. (Le.) chagasi Cunha \& Chagas, 1937, was the most common leishmania and it was found naturally infecting man, dog, opossum and the sandfly vector in the endemic area of visceral leishmaniasis of $\mathrm{Ba}$ hia. But also Le. (Le.) amazonensis s.l. was isolated from visceral human cases (Barral et al. 1986) and from opossum's blood (Sherlock et al. 1984,1988b) in Jacobina. Both species of leishmania were easily maintained in culture media and have easily infected hamster and Lu. longipalpis. However, dogs and opossum got the Le. chagasi 
infection only with much difficulty in my experiments.

I obtained only two infected among the 14 young dogs challenged by Le. chagasi, over two years of observation. In the same way, only 2 among 12 young opossum still marsupium-dependent, that were inoculated with the same species of leishmania, got the infection, over one year of observation. Furthermore, this leishmania caused a non evolutive disease in the 2 infected opossums (Sherlock et al. 1988a,b) and also in the 2 dogs that got the infection.

Le. chagasi showed the same degree of infectivity for hamster when injected together or without saliva of Lu. longipalpis, from Jacobina, in our laboratory (Sherlock \& Miranda 1993). Also I was never successful in infecting rats and Swiss mice over several months of observations after they were challenged by intraperitoneal injections of $L e$. chagasi

I was unable to experimentally transmit $L e$. chagasi by means of the bite of Lu. longipalpis in spite of persistent attempts, although I have succeeded in transmitting Le. (Le.) amazonensis by the bite of the same sandfly from an infected animal to another healthy animal (Tables I, II).
The vector - More than $90 \%$ of the sandflies are Lu. longipalpis (Lutz \& Neiva, 1912) in the endemic foci of visceral leishmaniasis of Bahia. In Jacobina, among the total 49,048 collected sandflies, 45,419 were Lu. longipalpis. The other species were Lu. lenti (Mangabeira, 1942), Lu. evandroi (Costa Lima \& Antunes, 1936), Lu. goiana Martins, Falcão \& Silva, 1962, and Lu. oswaldoi (Mangabeira, 1942). The sandfly fauna of the other foci of Bahia are similar to this one.

Only the two spotted Lu. longipalpis (with one white rounded spot on 3rd and 4th tergites) was found in Jacobina, whereas in Ipirá, a focus closely located, and in several other far endemic foci like, Jequié, Itaberaba, Monte Gordo, and so far, just one spotted Lu. longipalpis (on the 3rd tergite) was the only form found. But in Feira de Santana, a geographically intermediary focus, we found the two forms of sandflies.

Furthermore, among the population of the two spotted $\mathrm{Lu}$. longipalpis, one can also distinguish two sized forms existing sympatrically in Jacobina. One big, darker and haired and another smaller, clearer and naked.

The hourly biting activity of Lu. longipalpis in nature begins at dusk and reaches its highest peak

TABLE I

Experimental transmission of leishmanias to hamsters through bites, or injection of macerates, of eight days infected Lutzomyia longipalpis

\begin{tabular}{llrrr}
\hline & Infecting & \multicolumn{3}{c}{ Number of challenged hamsters } \\
\cline { 2 - 4 } Type of challenge & leishmanias & Used & Examined & Positive \\
\hline Bites of sandflies infected on naturally infected dogs & Le. chagasi & 22 & 19 & 0 \\
Bites of sandflies infected on hamsters & Le. amazonensis & 9 & 9 & 6 \\
Macerates of sandflies infected on naturally infected dogs & Le. chagasi & 19 & 16 & 0 \\
Macerates of infected sandflies on infected hamsters & Le. amazonensis & 2 & 2 & 1 \\
\hline
\end{tabular}

TABLE II

Negative attempts of transmission of Leishmania chagasi to hamsters, by bite, or injection of macerates, of infected Lutzomyia longipalpis

\begin{tabular}{lr} 
Type of challenge & $\begin{array}{r}\text { Number of } \\
\text { negative } \\
\text { attempts }\end{array}$ \\
\hline
\end{tabular}

Bites of suspected sandflies at the third day after collection in the endemic area of Grotinha, Jacobina 69

Macerates of naturally infected sandflies collected in the endemic area of Grotinha, Jacobina 6

Bites of infected laboratory bred sandflies, at the eighth day after feeding through membranes on suspensions of crushed infected hamsters spleens

Macerates of infected laboratory bred sandflies on the eighth day after feeding through membranes on suspensions of crushed infected hamsters spleens

Bites of eight days infected sandflies by feeding on naturally infected dogs from Grotinha, Jacobina 9

Macerates of eight days infected sandflies by feeding on naturally infected dogs from Grotinha, Jacobina 12 
from 9 to 11 p.m. After 11 p.m. the number of sandflies decreases until they totally disappear at 5-6 a.m. However, until 8-9 a.m., engorged females can still be collected inside houses, resting in shady places of bedrooms, or hidden behind beds, pictures and cracks of the walls. In the laboratory the sandfly feeds at any hour of the day.

There are seasonal fluctuations of the density of Lu. longipalpis in spite of its occurrence all over the year. It is more abundant during two periods: the months of June and November (Fig. 3). The vector abundance corresponds to the rainier colder and rainier hotter months. The seasonal fluctuations correlate with the forthcoming of new human cases and with the peridomestic frequency of opossums. Although Lu. longipalpis occurs during the whole month, it has a weekly variation according to the lunar phases. It is more frequent during both full moon and the last quarter moon (Fig. 4).

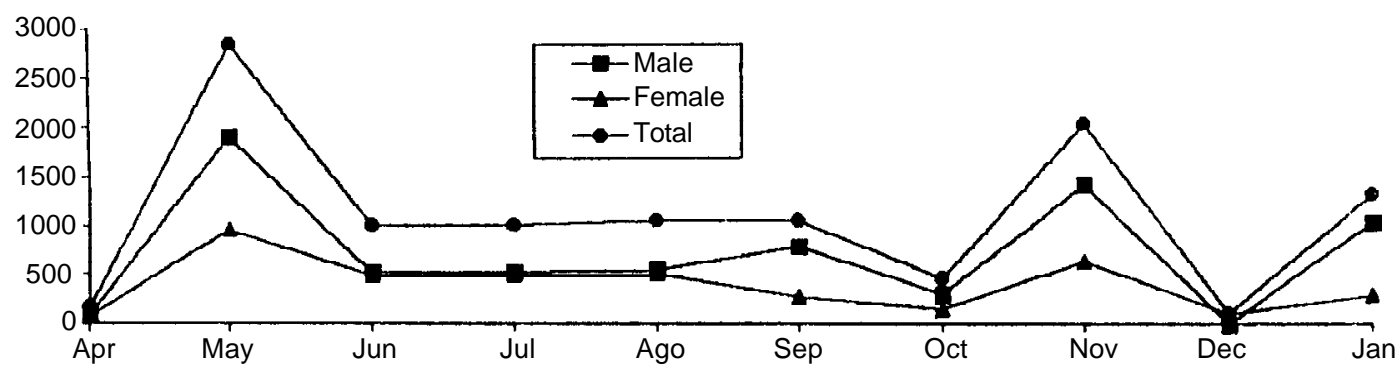

Fig. 3: seasonal fluctuations of the density of Lutzomyia longipalpis inside houses during the full moon phases, at Jacobina, State of Bahia, Brazil.

\section{house}

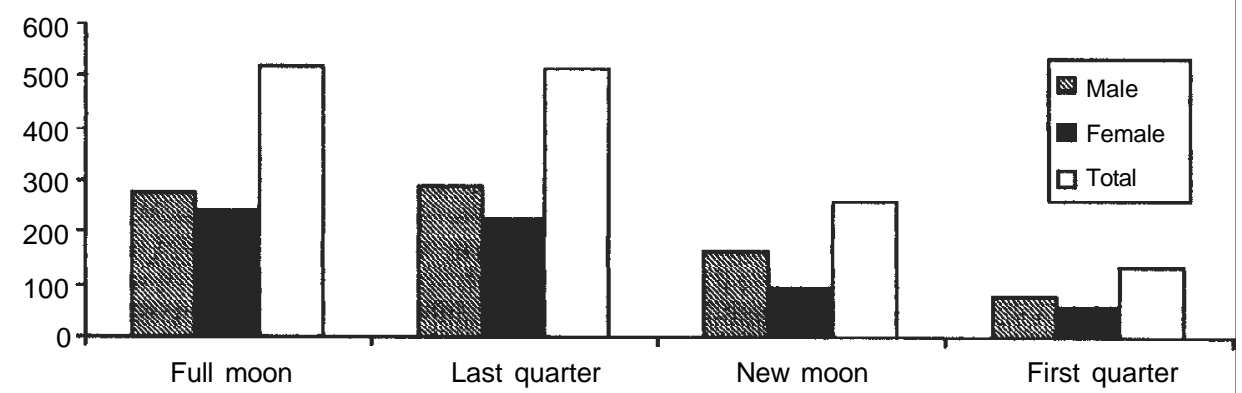

cave

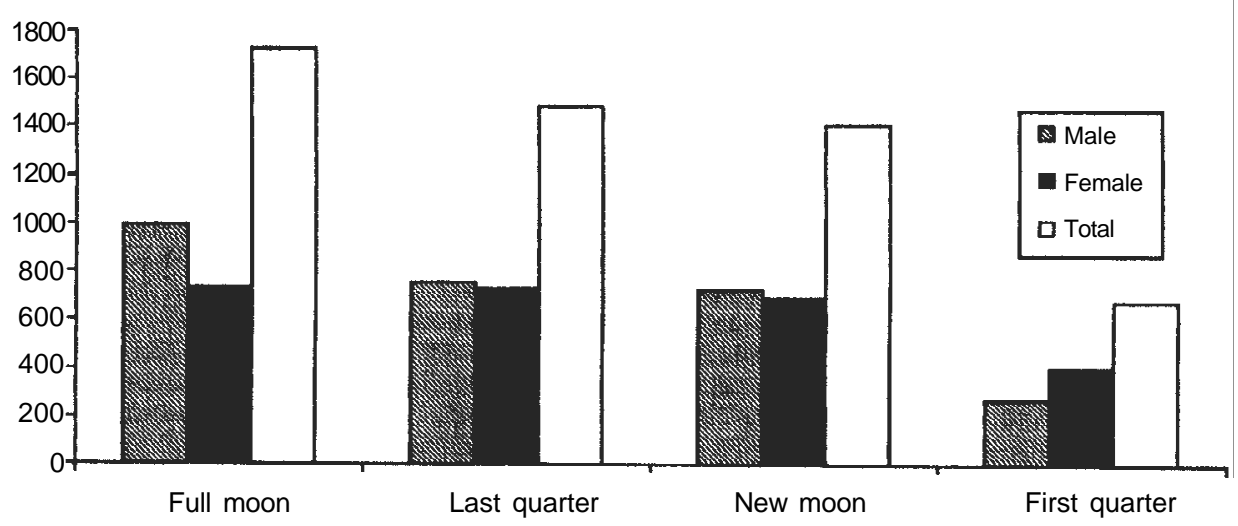

Fig. 4: variation, according to the lunar phases, of the density of Lutzomyia longiplapis inside houses and in caves of Jacobina, State of Bahia, Brazil. 
In the years of normal weather $L u$. longipalpis is abundant through all the area, including the natural shelters. However, during the droughts, it is much more found inside houses and peridomestic sites. This fact seems correlate with the periodical decennial epidemics of visceral leishmaniasis.

I have seen Lu. longipalpis feeding on caged opossum and on chicken, dogs and man in wild environments and in the laboratory where it has also fed very well on foxes.

I have infected $L u$. longipalpis with some strains of Le. chagasi from Brazil, and with Le. donovani from India and Le. infatum from Mediterran (Table III), but I was not successful in performing the experimental transmission of $L e$. chagasi from the bite of $L u$. longipalpis, although it was easily possible to obtain the transmission of Le. amazonensis (Tables I, II).

The two other more frequent species of sandfly in the endemic foci of Bahia, were Lu. lenti and Lu. evandroi, species, taxionomically close related. Although they are also very anthropophilic and fed on man, usually they prefer to get the blood meal on dogs and are found in large numbers in doghouses. Since one Lu. lenti specimen, collected on dog, was found naturally infected with promastigotes in Jacobina and both species are usually found together with Lu. longipalpis in the other endemic foci of visceral leishmaniasis of Brazil, I have suspected of their involvement in the transmission chain of Le. chagasi, mainly among dogs.

Natural breeding places of sandflies were not yet found in Jacobina. I have examined some suspected samples of materials collected in houses, chicken pens, corrals, caves and other resting places for numerous adults of $L u$. longipalpis from Jacobina and other foci but none of its developmental stages was obtained from such materials.

\section{Host and Reservoirs}

Domestic hosts - In the suburb of Jacobina,
Grotinha, among the total of 283 surveyed dwellings, domestic animals 245 (78 dogs, 62 cats, 18 goats, 3 donkeys, 19 pigs, and 65 chickens and ducks) were present. Besides man, dogs, cats and rats no other domestic mammals were examined for leishmanias.

Lu. longipalpis is attracted to feed on all these animals and man has a good attraction for it. At simultaneous collectings of sandflies made inside houses and in a cave, using different mammals as traps, the sandfly was collected in great number on chicken, man, dog and opossum, respectively in decreasing rates, but only on man there was predominance of collected females over the collected males. Donkeys are very attractive baits for either males or females of Lu. longipalpis while on pigs, goats and chicken more males were collected. Cats hardly attracted the vector. Opossum was not a good attractive bait for Lu. longipalpis but males and females were collected on it in the field.

Man -The results I have obtained on the capacity of man to infect Lu. longipalpis with leishmania were similar to those obtained by Deane (1956). My experiments revealed that in (33\%) two of six patients with visceral leishmaniasis who were submitted to xenodiagnosis with $L u$. longipalpis, only $15 \%$ of the sandflies were infected (Table IV). So, I can conclude that the role of man as reservoir seems not to be very significant, since man's capacity to infect the vector is poor. However, because of the increase in number of human cases during the epidemics and the growth of the density of Lu. longipalpis, the importance of man as reservoir also increases due to the existence of more opportunities for infection of the vector. This is suggested by the greater occurrence of new human cases, after the peak of seasonal fluctuation of Lu. longipalpis, in spite of the low rate of the sandfly natural infection that can be detected. It should also be emphasized that infected asymptomatic patients are much more frequent in the

TABLE III

Experimental infection of Lutzomyia longipalpis by feeding on infected hamsters with different leishmania species

\begin{tabular}{lccccc}
\hline \multirow{2}{*}{$\begin{array}{l}\text { Types of leishmania } \\
\text { infecting hamster }\end{array}$} & \multicolumn{2}{c}{ Challenges } & & \multicolumn{2}{c}{ No. of sandflies } \\
\cline { 2 - 3 } \cline { 5 - 6 } & Number & Positive & & Examined & Positive \\
\hline Le. braziliensis (man / Bahia) & 1 & 1 & & 28 & 1 \\
Le. chagasi (dog / Jacobina, Bahia) & 5 & 1 & & 85 & 8 \\
Le. chagasi (man / Imperatriz, Maranhão) & 3 & 1 & & 92 & 1 \\
Le. donovani (man / India) & 5 & 1 & & 82 & 10 \\
Le. infantum (man / Mediterran) & 3 & 1 & & 20 & 1 \\
\hline To t a l & 17 & 5 & 307 & 21 \\
\hline
\end{tabular}


endemic areas than are the patients with clinical disease, in the proportion of 18.1:1 (Badaró et al. 1986b). Le. chagasi was found in the skin of an asymptomatic patient and another asymptomatic patient infected Lu. longipalpis (Sherlock \& Sherlock 1961, Sherlock 1964). These facts could increase the importance of the man as a reservoir of Le. chagasi. Possibly the same fact happened with dogs as is described below.

Dogs - In 1982, 23.9\% of the dogs of Grotinha were seropositive, while at the same time, a small number of human cases occurred there (Table V). In 1984, the seropositivity rate of the dogs increased to $47.5 \%$ and at the same time a human epidemic occurred.

Usually, in the beginning of the infection, many dogs are asymptomatic and the amastigotes in their skin are scarce. Then they do not infect the sandflies well. The evolution of the disease increases the cutaneous parasitism, making the infection of the vector much easier. Then the dogs probably perform the role of the most important domestic reservoir, since besides they are very attractive for Lu. longipalpis, they also represent a better source for the infection of the vector than does man.

In my experiments $78 \%$ of dogs infected $29 \%$ of the sandflies, in $33 \%$ of the attempts, while man infected only $15 \%$ of the sandflies in $33 \%$ of the attempts. The results of Deane (1956) were $14.8 \%$ and $28.5 \%$ in 14 attempts for man and dogs, respectively.

Cats - I have examined 53 cats from Grotinha, Jacobina, by means of serology (IFT) and stained smears of the ears. In the skin of a cat, we found just one typical amastigote. This cat could not be re-examined and for this reason the specific identification of the amastigote was not made. All IFT of the cats were negative for Le. chagasi.

Domestic rodents - I have examined 20 specimens of Rattus rattus collected in Jacobina and none was confirmed to be infected with Le. chagasi. But recently, amastigotes were seen in the blood smears of two specimens of these rats and promastigotes were isolated in cultures from the same blood. Unfortunately the cultures were lost and the species of the flagellate was not identified. An additional 42 rodents, Mus musculus, were examined and were also negative for leishmanias. For this reason, no conclusion could be drawn from my observations on the importance of domestic rodents as reservoirs of visceral leishmaniasis in Jacobina (Table VI).

Sylvatic or commensal reservoirs - In Grotinha 3,353 traps were set during the years of 1982 to 1984 of which only $166(5 \%)$ caught 178 specimens of mammals. The results mean that there was a very poor fauna existing in the periphery of Jacobina, mainly belonging to only 11 species of mammals.

The predominant species was the black ear marsupial opossum that made up $44 \%$ of the total of the collected mammals. Following this were the rodents with a frequency of $39 \%$. However, the sylvatic rodents were less frequent than the domestic ones. More 10 agoutis, 7 guinea-pigs, 6 armadillos and only 14 foxes were obtained with much difficulty, even though attractive financial offers were made to buy foxes from hunters.

TABLE IV

Capacities of the hosts man, dog and opossum to infect Lutzomyia longipalpis with Leishmania chagasi from Jacobina, State of Bahia

\begin{tabular}{|c|c|c|c|c|c|c|c|}
\hline \multicolumn{2}{|c|}{$\mathrm{Host}$} & \multicolumn{3}{|c|}{ A t t e mpts } & \multicolumn{3}{|c|}{ Sandflies } \\
\hline Type & Number & Examined & Positive & $\%$ & Examined & Positive & $\%$ \\
\hline Man & 2 & 6 & 2 & 33 & 201 & 32 & 15 \\
\hline Dog & 8 & 20 & 13 & 78 & 368 & 107 & 29 \\
\hline Opossum & 1 & 8 & 2 & 25 & 193 & 27 & 14 \\
\hline
\end{tabular}

TABLE V

Dogs positive for visceral leishmaniasis in Grotinha, Jacobina, State of Bahia, in the years of 1982 and 1984 , by serology (IFT) and stained smears of ears'skin

\begin{tabular}{|c|c|c|c|c|c|c|}
\hline \multirow[t]{3}{*}{ Year $^{a}$} & \multicolumn{6}{|c|}{ Number of dogs examined } \\
\hline & \multicolumn{3}{|c|}{ Serology (IFT) } & \multicolumn{3}{|c|}{ Smears } \\
\hline & Examined & Positive & $\%$ & Examined & Positive & $\%$ \\
\hline 1982 & 46 & 11 & 23.9 & 46 & 1 & 2.0 \\
\hline 1984 & 40 & 19 & 47.5 & 42 & 5 & 12.0 \\
\hline
\end{tabular}

$a$ : the positive ones were killed soon after the results 
From 1985 to 1991,75 mammals more were still examined: 35 opossums and 30 wild and domestic rats (Table VI).

Opossums - The species of the black ear opossum was Didelphis albiventris Lund, 1841. Among 119 specimens examined 4 were infected with three species of leishmanias: 2 with Le. chagasi, 1 with Le. amazonensis and 1 with Le. braziliensis like.

The histopathologic examination of the two opossum specimens naturally infected with $L e$. chagasi showed proliferation of macrophage cells but did not reveal parasites or typical evolutive lesions of visceral leishmaniasis. Also, the histopathologic examination of experimentally infected specimens, with the same opossum strain of Le. chagasi, only revealed amastigotes in the spleen, and liver granuloma formation, as in the non evolutive forms of visceral leishmaniasis (Sherlock et al. 1988b).

D. albiventris was captured throughout the year but during the rainy and colder months of May, June, July and August, the number of specimens collected was higher. This monthly variation of the opossum population correlates with the highest density of $L u$. longipalpis and the onset of new human cases of visceral leishmaniasis in Jacobina. During these months the opossum frequents the human's dwellings, more often, looking for food. Besides leftovers from human meals, they also eat chickens, eggs and fruit. D. albiventris was the only wild mammal to be found infected with Le. chagasi around houses in Jacobina. In two houses close to the one where the infected opossums were captured, human and canine cases of visceral leishmaniasis were registered. Lu. longipalpis feeds readily on $D$. albiventris in the laboratory.

Foxes - The fox Lycalopex vetulus (Lund, 1842) can be seen, during the night, crossing the roads near endemic foci of Bahia. Sometimes they are killed by cars or shot by the hunters during the night. It is not easy to catch foxes alive and for this reason only 14 specimens, bought from local hunters, were examined from Jacobina and another 13 from the endemic focus of Jequie in the State of Bahia. All these 27 specimens were apparently healthy and leishmanias were not detected in their

TABLE VI

Mammals caught in Jacobina, State of Bahia, from 1982 to 1992 and examined for natural infection with leishmania

\begin{tabular}{|c|c|c|c|c|c|c|}
\hline \multirow[b]{2}{*}{ Species } & \multicolumn{2}{|l|}{ Mammals } & \multicolumn{4}{|c|}{ Infected with } \\
\hline & Captured & Examined & $\begin{array}{c}\text { Le. } \\
\text { chagasi }\end{array}$ & $\begin{array}{c}\text { Le. } \\
\text { amazonensis }\end{array}$ & $\begin{array}{c}\text { Le. } \\
\text { braziliensis }\end{array}$ & Amastigotes $^{a}$ \\
\hline $\begin{array}{l}\text { Dasyprocta aguti } \\
\text { (agouti) }\end{array}$ & 10 & 9 & - & - & - & 4 \\
\hline $\begin{array}{l}\text { Didelphis albiventris } \\
\text { (opossum) }\end{array}$ & 152 & 119 & 2 & 1 & 1 & - \\
\hline $\begin{array}{l}\text { Cabassous unicinctus } \\
\text { (armadillo) }\end{array}$ & 6 & 6 & - & - & - & - \\
\hline $\begin{array}{l}\text { Callithrix penicillata } \\
\text { (marmoset) }\end{array}$ & 1 & 1 & - & - & - & - \\
\hline $\begin{array}{l}\text { Cavia porcellus } \\
\text { (Guinea pig) }\end{array}$ & 7 & 6 & - & - & - & - \\
\hline $\begin{array}{l}\text { Cercomys cunicularius } \\
\text { (wild rat) }\end{array}$ & 17 & 16 & - & - & - & 1 \\
\hline $\begin{array}{l}\text { Chiroptera } \\
\text { (bat) }\end{array}$ & 1 & 1 & - & - & - & - \\
\hline $\begin{array}{l}\text { Lycalopex vetulus } \\
\text { (fox) }\end{array}$ & 14 & 14 & - & - & - & - \\
\hline $\begin{array}{l}\text { Mus musculus } \\
\text { (domestic mouse) }\end{array}$ & 47 & 42 & - & - & - & - \\
\hline $\begin{array}{l}\text { Oryzomis eliurus } \\
\text { (rice rat) }\end{array}$ & 16 & 14 & - & - & - & 1 \\
\hline $\begin{array}{l}\text { Oryzomis subflavus } \\
\text { (rice rat) }\end{array}$ & 1 & 1 & - & - & - & - \\
\hline $\begin{array}{l}\text { Rattus rattus } \\
\text { (black rat) }\end{array}$ & 40 & 39 & - & - & - & 2 \\
\hline Total & 312 & 268 & 2 & 1 & 1 & 8 \\
\hline
\end{tabular}

$a$ : species not identified 
spleen, liver and skin by means of microscopic examination of stained smears. The specimens from Jacobina were also examined by IFT and by spleen culture in NNN and inoculation into hamsters. More observation about this matter, including follow up of the infection with Le. chagasi in the foxes, are necessary.

Wild rodents - Structures resembling leishmania amastigotes were seen in smears of liver and spleen of four specimens of Dasyprocta aguti and in smears of spleen of a Cercomys cunicularius and a Oryzomys eliurius. Unfortunately, they could not be isolated and specifically confirmed as leishmania (Table VI).

\section{DISCUSSION}

Some factors that interact in the ecology of the visceral leishmaniasis in Bahia are practically the same of the ones observed in other areas of Brazil as the poverty, malnourished inhabitants, several children with symptomatic visceral leishmaniasis, large number of infected dogs, high density of sandfly in houses, and a not yet clear factor that could be the existence of a primary reservoir which starts the epidemiological dynamic of the disease. This primary reservoir seems to be important for both existing hypothesis either of a native or of an imported leishmanial parasite

Analysis of epidemiological risk factors for the development of the disease in Jacobina revealed the age 0 to 5 years as the main factor, followed by the bad nutritional status. Thus $75 \%$ of the malnourished children, when infected, developed severe symptoms. The serological rate for positive antibodies, predominates in children above 5 years of age. There is a greater number of asymptomatic seropositive children than with typical clinical disease. Most of the human cases in Jacobina have acquired visceral leishmaniasis around their houses (Badaró et al. 1986a,b, Badaró 1988).

The increase of the incidence of visceral leishmaniasis and its fast dispersion in the last two decades, in the State of Bahia, as in Brazil, is probably in part a consequence of the drastic predatory action of man on the natural environments. The deep modifcation of the sylvatic ecosystems caused by deforestation, oblige sylvatic animals to encroach on the places near the human dwelings, looking for food and shelter. Also Lu. longipalpis has been well established in the peridomestic sites because the environmental changes caused by new settlements in the rural zones and the suitable environmental conditions created for the sandfly in the periphery of big cities, where the ecological man - domestic animal - sylvatic animal interaction with the vector of Le. chagasi has increased once more. Also, the reduction in the spraying of insecticides for control of the malaria vectors has possibly played a role to ease the density and dispersion of the vector enlarging the limits of visceral leishmaniasis.

In addition, besides the new ones, the old endemic foci continued to be epidemiologicaly important since it was impossible to maintain permanent control measures over there, like in Jacobina and Jequié, our basic areas of studies.

The periodical epidemics of visceral leishmaniasis seems to be correlated with the nutritional and immunological status of the individuals, mainly among 0 and 5 years of age that are challenged by the parasite. Also climatic factors and ecological unbalances are probably important connections. Periodical droughts provoke a successive chain of interrelated factors, such as farming devastation, scarcity of food and decrease of the nutritional and immunological condition of the population at risk. In other way, the drought periods increase the contact of man with the sylvatic reservoirs and vector, encroached on the peridomestic environment, facilitating the transmission of the disease.

According to our hypothesis on the decennial periodicity, the year 1995 is the end of the epidemic cycle of 1993, when a lot of cases have occurred in Bahia and the number of new cases begin to fall. It is valuable to increase the knowledges on the periodical occurrence of visceral leishmaniasis since it can lead away more properly the control measures at the right time.

In the State of Bahia, Le. amazonensis s. $l$. is also a causative species of visceral leishmaniasis. But I have been thinking on the possibility of this leishmania being either a visceratropic new species, close related to the real Le. amazonensis. Also, it can be speculated, based on the hypothesis of Warburg et al. (1994), who thinks that the diverse compositions of the saliva of the alopatric $L u$. longipalpis sibling species have unequal capacities to enhance the same leishmania to modulate different pathogenies. So, as Lu. flaviscutellata, the natural vector of Le. amazonensis was never found in Jacobina, possibly Lu. longipalpis, the substitute vector, would be modulating Le. amazonensis to cause visceral leishmanisasis, instead of cutaneous leishmaniasis. In other way, it still may be that $\mathrm{Lu}$. longipalpis is also the natural vector of a new parasite that has been identified to date as Le. amazonensis.

The main bases for assuming of Lu. longipalpis as the most important vector of American visceral leishmaniasis in Bahia were exclusively ecological, such as: its coincidental geographical distribution with that of human and canine visceral leishmaniasis; its natural infection in the same locations as the human cases; its pronounced antropophilic 
habits, feeding frequently on man. Although I have infected Lu. longipalpis with Le. chagasi after feeding on infected man and dog, I have never demonstrated the formal proof of transmission of $L e$. chagasi by the bite of Le. longipalpis in the laboratory. Otherwise, only recently, some records of experimental transmissions of Le. chagasi, from an infected to a healthy mammal, by the bite of $L u$. longipalpis, were obtained in the laboratory (Gonçalves et al. 1985, Ward et al. 1988a, Lainson et al. 1990). Even so, it is important to emphasize that artificial procedures were employed in some of these successful experiments. Blood suspensions of macerates of highly infected hamsters spleens with amastigotes, were used to infect the vector through membranes, instead of feeding and infecting the sandfly on living infected animals. I have observed that the behaviour and life cycle of $L e$. chagasi in the digestive tract of Lu. longipalpis can follow different ways depending upon the method used for infection of the sandfly. This fact may have influenced the success of the positve results of the formal experimental proof of transmission of Le. chagasi by the bite of Lu. longipalpis.

In nature, a high density of vector seems to be necessary to have an epidemiological risk level of transmission, since the natural infection rate of the sandflies is usually very low in the endemic foci (Deane 1956, Sherlock \& Miranda 1992). Only during epidemics, infected sandflies are found more in nature, even so in small numbers. In Jacobina I have obtained on two different opportunities the following natural infection rates of $L u$. longipalpis: in the 1965/1967 endemic period, among 1,528 sandflies were examined, none was found infected, while in the $1983 / 1985$ periodical epidemic cycle, among 3,734 sandflies were examined eight were infected with promastigotes $(0.2 \%)$.

Lu. longipalpis was more abundant during full moon and last quarter, on contrary other sandfly species that were collected more in the new moon (Aguiar \& Vilela 1987).

I have not perceived any epidemiological implication about the existence of Lu. longipalpis with different number of spots in the tergites. Ward et al. (1988b) have speculated about the possibility that there are different capacities of transmission of leishmanias in accordance with the spotted type of the vector. Lanzaro et al. (1993) has found genetic divergence and interspecific hybrid sterility among three populations of $\mathrm{Lu}$. longipalpis and concluded that this sandfly is a species complex, as was already suggested by Mangabeira (1969).

Regarding the presence of two sizes of $L u$. longipalpis in Bahia, I have considered that this fact is due to the different ages of the individuals among the population of sandflies. Both forms of $\mathrm{Lu}$. longipalpis can be seen in our laboratory colony, and the smaller and naked specimens seem to be the older ones that have lost seta and hairs. It may be of practical interest as an indication of the proximity of the breeding places of the bigger, haired and darker younger individuals that could be the ones recently born in the neighbouring areas. Whereas the elder, smaller and naked individuals, probably have come from faraway and are recent invaders of the location. This is suggested by the fact that after spraying insecticides, the first population that began to appear in the area, is composed mainly by the smaller naked type that probably came from more distant places not sprayed. Or rather, the two types could be just individuals well or badly nourished of the same population of sandflies.

The species of leishmanias produce mild or asymptomatic infection in their natural hosts, maintaining the balance in the relationship between parasite/host (Deane 1956, Lainson 1983). Commonly man, dog and fox in northwest of Brazil, have a fatal infection with Le. chagasi; thus, they are not well adapted as natural reservoirs of the parasite. Like man, they seem to be recent hosts that strongly suffer from the disease. This fact, according to Lainson (1983), has been used as an argument for the support of the hypothesis of other authors that visceral leishmaniasis was caused by Le. infantum imported by means of dogs.

From the epidemiological point of view, regardless of whether or not dogs suffer from visceral leishmaniasis, they constitute the main domestic source for infection of the vector in Bahia, although they are also great victims of the disease. Besides, they can attract and infect the vector very well, it seems that dogs can also be implicated in the sylvatic cycles. They could carry leishmanias from the domestic sites to the forests or vice-versa, when they are following the hunters in the field. Recently some papers have emphasized the approximation of Lu. longipalpis to foxes in wild environments when the infection and transmission of the disease could be performed (Lainson et al. 1990, Quinnel et al. 1992).

It seems that a usually canine epizootic precedes the human epidemic and continues thereafter in an endemic fashion. However, another primary wild reservoir must also exist sympatrically with man, dogs and vector, in order to explain some obscure aspects in the natural history of the disease.

It is possible that in Bahia, as in other foci of Brazil, cats do not have any importance as a reservoir of Le. chagasi. In some important foci of visceral leishmaniasis in the northeast of Brazil, Deane 
(1956) examined 142 cats and all were negative for leishmania. Also, Alencar et al. (1974/75), have examined 214 cats, from the State of Ceará and all cats had negative results. Cats almost never attract Lu. longipalpis and until now, besides this one mentioned here, only one other cat was found naturally infected with a non specified amastigote in the State of Pará.

Foxes were first found naturally infected in America, in the endemic focus of the northeast of Brazil, by Deane (1956). These four first foxes infected, that were identified as Ly. vetulus were sick with identical symptomatology as the dogs. The total of 7 Ly. vetulus were infected among 173 examined from the State of Ceará, were also sick, according to Alencar et al. (1974/75). But later, an additional 6 other foxes Cerdocyon thous, apparently healthy, were found infected among 20 examined by Lainson et al. (1990) in the north of Brazil. Since there was such a significant number of infected foxes without symptoms, it was speculated that American visceral leishmaniasis could have originated from old American sylvatic cycles involving foxes (Lainson 1983). Later, Lainson et al. (1990) mentioned further records of innaparent infections in foxes from the Marajó Island, State of Pará, culminating in a total of 11 isolations of Le. chagasi among 26 specimens examined and more 12 out of 22 other foxes with positive IFT from the same area. None of those foxes had shown any abnormal behavior or signs of ill-health. They concluded that there may be an enzootic focus of Le. chagasi maintained by foxes and $L u$. longipalpis in sylvatic habitat, serving as a source from which canine and human disease may arise. But I still do not exclude the possibility of foxes being infected with the same leishmania introduced in the sylvatic incursions by dogs, or in the peridomestic sites, when the foxes visit them for food.

Foxes and domestic rodents were not found naturally infected in the State of Bahia. But a few apparently healthy foxes in which I performed examination for leishmania and obtained negative results, did not allow me to drawn definitive conclusions. Based on Lainson (1983) and Lainson et al. (1990), I think that foxes usually have asymptomatic leishmaniasis and in this condition it is not easy to find and isolate parasite from its organs. Therefore, it is necessary to continue observations about the role of this canidae in the ecology of visceral leishmaniasis in Bahia.

Years ago, after the use of control measures, I speculated about the possibility of the involvement of domestic rats in the chain of transmission of visceral leishmaniasis in Jacobina (Sherlock \& Almeida 1969). But an insignificant number of rats was examined at that time, because an epizootic of bubonic plague had decimated the population of the rodents, at the same time that visceral leishmaniasis had disappeared from Jacobina. Our recent observations in Jacobina did not show any $R$. rattus infected with Le. chagasi, in spite of the fact I have found several amastigotes not specifically identified in blood smears from it and isolated promastigotes in blood cultures from this rodent. $R$. rattus and $R$. norvegicus have been found naturally infected with Le. infantum in the Mediterranean and in Next Orient endemic areas (El-Adhami 1976, Pozzio et al. 1981). Alencar et al. (1974/75), found amastigotes in a $R$. rattus in the State of Ceará, which Lainson (1983) believed to be $L e$. chagasi. Also, the finding of some infected rodents with leishmania in Central America, is believed by Lainson (1983) to be Le. chagasi. But the leishmania species of these findings could not be established.

D. albiventris was the first non canidae mammal to be shown naturally infected with Le. chagasi in the American Continent (Sherlock et al. 1984, 1988a,b). Soon after, several infected $D$. marsupialis were diagnosed with the same leishmania in endemic focus of Colombia (Corredor et al. 1989).

This American marsupial does not suffer from the pathogenic action of Le. chagasi. The fact seems to indicate the existence of an evolved host/ parasite association that permits this marsupial probably to be one of the primary reservoirs of American visceral leishmaniasis. However, in spite of some evidence, one can not yet eliminate the hypothesis also that the opossum in its approximation to man, has been infected with the same leishmania that was infecting man, dogs or other reservoirs inthe domestic or peridomestic sites.

In conclusion, I would like to emphasize that the picture of the ecology and epidemiological characteristics of the visceral leishmaniasis, remains partially unclear. In spite of the researches that have been carried out during decades, more multidisciplinairy studies are necessary to answer numerous outstanding questions. Only then, it will be possible to conduct more efficiently the methods for the control of visceral leishmaniasis.

\section{REFERENCES}

Aguiar GM, Vilela M 1987. Aspects of the ecology of sandflies at the Serra dos Órgãos, National Park, State of Rio de Janeiro. VI - Shelters and breeding places (Diptera, Psychodidae, Phlebotominae). Mem Inst Oswaldo Cruz 82: 585-586.

Alencar JE de 1959. Calazar Canino. Contribuição para o estudo da epidemiologia do Calazar no Brasil. Imprensa Oficial, Fortaleza, Ceará, 342 pp.

Alencar JE de, Almeida YM, Silva ZF, Paiva AS, Fonseca MF 1974/75. Aspectos atuais do calazar no 
Ceará. Rev Brasil Malar Doenças Trop 26: 27-53.

Badaró R 1988. Progress of research in visceral leishmaniasis in the endemic area of Jacobina, Bahia, 1934-1989. Rev Soc Brasil Med Trop 21:159-164.

Badaró R, Jones TC, Lourenço R, Cerf BJ, Sampaio D, Carvalho EM, Rocha H, Teixeira R, Johnson Jr WD 1986b. A prospective study of visceral leishmaniasis in an endemic area of Brazil. J Infec Dis 154: 639-649.

Badaró R, Jones TC, Carvalho EM, Sampaio D, Reed SG, Barral A, Teixeira R, Johnson Jr WD 1986a. New perspectives on a sub clinical form of visceral leishmaniasis. J Infec Dis 156: 1003-1011.

Barral A, Badaró R, Barral Netto M, Grimaldi Jr G, Momen H, Carvalho EM 1986. Isolation of Leishmania amazonensis from the bone marrow in a case of American visceral leishmaniasis. Amer J Trop Med Hyg 35: 732-734.

Corredor A, Gallego JF, Tesh RB, Pelaez D, Diaz A, Montela M, Paulase MT 1989. Didelphis marsupialis an apparent wild reservoir of Leishmania donovani chagasi in Colombia, South America. Trans R Soc Trop Med Hyg 83: 195.

Costa CHN, Pereira HF, Araujo MV 1990. Epidemia de leishmaniose visceral no Estado do Piauí, Brasil 1980-1986. Rev Saúde Púb S Paulo 24: 361-372.

Cunha S, Freire M, Eulalio C, Cristóvão J, Netto E, Johnson Jr WD, Reed SG, Badaró R 1995. Visceral leishmaniasis in a new ecological niche near a major metropolitan area of Brazil. Trans $R$ Soc Trop Med Hyg 89: 155-158.

Deane LM 1956. Leishmaniose visceral no Brasil. Estudos sobre reservatórios e transmissores realizados no Estado do Ceará. Serviço Nacional de Educação Sanitária, Rio de Janeiro, Brasil, 162 pp.

El-Adhami B 1976. Isolation of leishmania from a black rat in the Baghdah area. Iraq Med J Trop Med Hyg 25: 759-761.

Grimaldi Jr G, Tesh RB, Pratt DM 1989. A review of the geographic distribution and epidemiology of leishmaniasis in the New World. Amer J Trop Med Hyg 41: 687-725.

Gonçalves M de NA, Ryan L, Lainson R, Shaw JJ 1985. The retained capacity of Lutzomyia longipalpis (Lutz \& Neiva) to transmit Leishmania chagasi (Cunha \& Chagas) after eight years in a closed laboratory colony. Mem Inst Oswaldo Cruz 80: 337-338.

Jeronimo SMB, Oliveira RM, Mackay S, Costa RM, Sweet J, Nascimento ET, Jernigan J, Pearson RD 1994. An urban outbreak of visceral leishmaniasis in Natal, Brazil. Trans $R$ Soc Trop Med Hyg 88: 386-388.

Lainson R 1983. The American leishmaniases: some observations on their ecology and epidemiology. Trans $R$ Soc Trop Med Hyg 77: 569-596.

Lainson R, Dye C, Shaw JJ, Macdonald D, Courtenay O, Souza AA, Silveira FT 1990. Amazonian visceral leishmaniasis: distribution of the vector Lutzomyia longipalpis (Lutz \& Neiva) in relation to the fox Cerdocyon thous (L.) and the efficiency of this reservoir host as a source of infection. Mem Inst Oswaldo Cruz 85: 135-137.
Lanzaro GC, Ostrovska K, Herrero MV, Laywer PG, Warburg A 1993. Lutzomyia longipalpis is a species complex: genetic divergence and interspecific hybrid sterility among three populations. Amer $J$ Trop Med Hyg 48: 839-847.

Lopes JAS, Sarno P 1956. Leishmaniose visceral canina em Jacobina, Bahia. Boletim da Fundação Gonçalo Moniz 11: 1-11.

Mangabeira Filho O 1969. Sôbre a sistemática e biologia dos Phlebotomus do Ceará. Rev Brasil Malar Doenças Trop 21: 3-26.

Marzochi MCA, Marzochi KBF 1994. Tegumentary and visceral leishmaniases in Brazil - Emerging antropozooonosis and possibilities for their control. Cad Saúde Púb 10: 359-375.

Momen H, Grimaldi Jr G, Deane LM 1987. Leishmania infantum, the aethiological agent of the American Visceral leishmaniasis (AVL). Mem Inst Oswaldo Cruz 82: 447-448.

Penna HA 1934. Leishmaniose visceral no Brasil. Brasil Médico 18: 940-950.

Pessoa SB, Silva LHP da, Figueiredo J 1955. Calazar endêmico em Jacobina (Estado da Bahia). Rev Brasil Malar Doenças Trop 7: 245-250.

Pozzio E, Gradoni L, Bettini S, Gramiccia M 1981. Leishmaniasis in Tuscani (Italy) V. Further isolation of leishmania from Rattus rattus in the province of Grosseto. Ann Trop Med Parasitol 75: 393-395.

Quinnel RJ, Dye C, Shaw JJ 1992. Host preferences of the phlebotomine sandfly Lutzomyia longipalpis in Amazonian Brazil. Med Veter Entomol 6: 195-200.

Shaw J 1993. Taxonomy of the genus Leishmania. Present and future trends and their implications, $\mathrm{p}$. 7-18. In S Brandão-Filho, Research and control of leishmaniasis in Brazil. Proceedings of a National Workshop. Fundação Oswaldo Cruz-Centro de Pesquisas Aggeu Magalhães, Recife, PE, Brazil.

Sherlock IA 1964. Surto de Calazar na Zona Central do Estado da Bahia. Rev Brasil Malar Doenças Trop 16: 157-170.

Sherlock IA 1969. Observações sobre calazar em Jacobina, Bahia. I - Histórico e dados preliminares. Rev Brasil Malar Doenças Trop 21: 523-534.

Sherlock IA 1987. Periodicidade epidêmica da leishmaniose visceral no Brasil. Rev Soc Brasil Med Trop 20: 103.

Sherlock IA 1992. Is vector and reservoir control possible for leishmaniases? In $\mathrm{P}$ Wijeyaratne, $\mathrm{T}$ Goodman, C Spinal (eds). Leishmamiasis Control Strategies. A critical evaluation of IDRC supported research. IDRC MR 322e vol I, $380 \mathrm{pp}$.

Sherlock IA, Almeida SP 1969. Observações sobre calazar em Jacobina, Bahia. V Resultados de medidas profiláticas. Rev Brasil Malar Doenças Trop 22: 175-182.

Sherlock IA, Almeida SP 1970. Notas sobre leishmaniose canina no Estado da Bahia. Rev Brasil Malar Doenças Trop 22: 2312-242.

Sherlock IA, Guitton N 1969a. Observações sobre calazar em Jacobina, Bahia. III Alguns dados sobre o Phlebotomus longipalpis, o principal transmissor. Rev Brasil Malar Doenças Trop 21: 541-548. 
Sherlock IA, Guitton N 1969b. Observações sobre calazar em Jacobina, Bahia. IV Variação horária e estacional do Phlebotomus longipalpis. Rev Brasil Malar Doenças Trop 21: 715-728.

Sherlock IA, Miranda JC 1992. Observations on the ecology of visceral leishmaniasis in Jacobina, State of Bahia, Brazil (1982-1986) p. 54-80. In $\mathrm{P}$ Wijeyaratne, T Goodman, C Spinal (eds). Leishmaniasis Control Strategies: A critical evaluation of IDRC supported research. IDRC-MR 322e vol I, $380 \mathrm{pp}$.

Sherlock IA, Miranda JC 1993. Ausência de ação do lisado de glândula salivar de Lutzomyia longipalpis na infectividade de Leishmania chagasi in hamster. Rev Soc Brasil Med Trop 26: 233.

Sherlock IA, Pessoa SB 1964. Métodos práticos para a captura de flebótomos. Rev Brasil Biol 24: 331-340.

Sherlock IA, Santos AC 1964. Leishmaniose visceral na zona de Jequié, Estado da Bahia. Rev Brasil Malar Doenças Trop 16: 442-448.

Sherlock IA, Sherlock VA 1961. Sobre a infecção experimental de Phlebotomus longipalpis pela Leishmania donovani. Rev Brasil Biol 21: 409-418.

Sherlock IA, Sherlock VA 1972. Tentativa de transmissão da Leishmania donovani pela picada de Lutzomyia longipalpis, entre cães. Rev Soc Brasil Med Trop 6: 35-39.

Sherlock IA, Miranda JC, Sadigursky M, Grimaldi Jr G 1984. Natural infection of the opossum Didelphis albiventris (Marsupialia Didelphidae) with Leishmania donovani in Brazil. Mem Inst Oswaldo Cruz, 79: 511.
Sherlock IA, Miranda JC, Sadigursky M, Grimaldi Jr G 1988a. Experimental infection of the opossum Didelphis albiventris (Marsupialia Didelphidae) with Leishmania donovani. Mem Inst Oswaldo Cruz 83: 141.

Sherlock IA, Miranda JC, Sadigursky M, Grimaldi Jr G 1988b. Observações sobre calazar em Jacobina, Bahia. Investigação sobre reservatórios silvestres e comensais. Rev Soc Brasil Med Trop 21: 23-27.

Sherlock IA, Miranda JC, Santoro F 1987. Ecologia da leishmaniose visceral em área endêmica de Jacobina, Bahia. III Tentativas de transmissão de leishmanias, de hamster para hamster, através da picada e com triturados de L. longipalpis. Resumos do $\mathrm{X}$ Congresso da Sociedade Brasileira de Parasitologia, Salvador, Bahia, 154pp.

Teixeira R 1980. Experiências vividas com leishmaniose visceral 1954\1980 (Aspectos epidemiológicos e evolutivos). Thesis, Faculdade de Medicina da Universidade Federal da Bahia, Salvador, BA, 313 pp.

Warburg A, Saravia E, Lanzaro GC, Titus RG, Neva F 1994. Saliva of Lutzomyia longipalpis sibling species differs in its composition and capacity to enhance leishmaniasis Philos. Trans $R$ Soc London B Biol Science 345: 223-230.

Ward RD, Lainson R, Shaw JJ 1988a. Some methods for membrane feeding of laboratory reared neotropical sandflies (Diptera : Psychodidae). Ann Trop Med Parasitol 72: 269-276.

Ward RD, Phillips A, Burnet B, Marcondes CB 1988b. Biosystematics of Haematophagous Insects, Systematics Association Special V.37:257-269. Claredon Press, Oxford, England. 
Ecological Interactions of Visceral Leishmaniasis in Bahia - IA Sherlock 